\title{
Partial reinforcement and classical conditioning in two species of fish'
}

ERIKA R. BEHREND AND M. E. BITTERMAN, DEPARTMENT OF PSYCHOLOGY, BRYN MAWR COLLEGE, Bryn Mawr, Pa. 19010

A classical conditioning experiment patterned after one which earlier had produced the PRE in African mouthbreeders produced the effect again in mouthbreeders, but failed to produce it in goldfish. The implications of the results for the problem of partial reinforcement in classical conditioning are considered.

A series of recent experiment on classical conditioning in goldfish failed to show the PRE (if that effect is defined in terms of the over-all level of response in extinction), although some indication of greater resistance in partial Ss appeared in the form of groups by trials and groups by days interactions (Berger, Yarczower, \& Bitterman, 1965). In the experiment here to be reported, we tried again to find the effect in goldfish with a procedure which has produced it in African mouthbreeders (Gonzalez, Eskin, \& Bitterman, 1963). We hoped that the outcome would help to understand the results of recent experiments with other vertebrates which suggest that the PRE is produced much more readily by instrumental than by classical techniques (Fitzgerald, 1966; Thomas \& Wagner, 1964; Slivka \& Bitterman, 1966; Wagner, Siegel, \& Fein, 1967). Both goldfish and mouthbreeders show the effect in instrumental experiments (Gonzalez \& Bitterman, 1967).

Method. The Ss were 60 goldfish, about 3 in. long, which were obtained from a local dealer, and 42 African mouthbreeders (Tilapia macrocephala), of about the same length, which were bred in the laboratory. All Ss were experimentally naive. They were maintained in individual 2-gal tanks, filtered and aerated, in temperature-regulated laboratory rooms ( $75 \operatorname{deg} F$ for the goldfish and $80 \mathrm{deg} F$ for the mouthbreeders).

A diagram of the apparatus and a detailed description of the conditioning technique may be found in an earlier paper (Bitterman, 1964). The basic procedure was to pair light (CS) with shock (US) and to measure the generalized activity which the light came in consequence to evoke. Activity was detected by a paddle attached to a rod inserted into the needle-holder of a crystal phonograph cartridge, the output of which was amplified and used to drive a printing counter. All of the events of the experiments were programmed automatically.

The design of the experiment was like that of the earlier mouthbreeder experiment (Gonzalez, Eskin, \& Bitterman, 1963). Two groups of goldfish and two groups of mouthbreeders were trained for 20 days with a CS-US

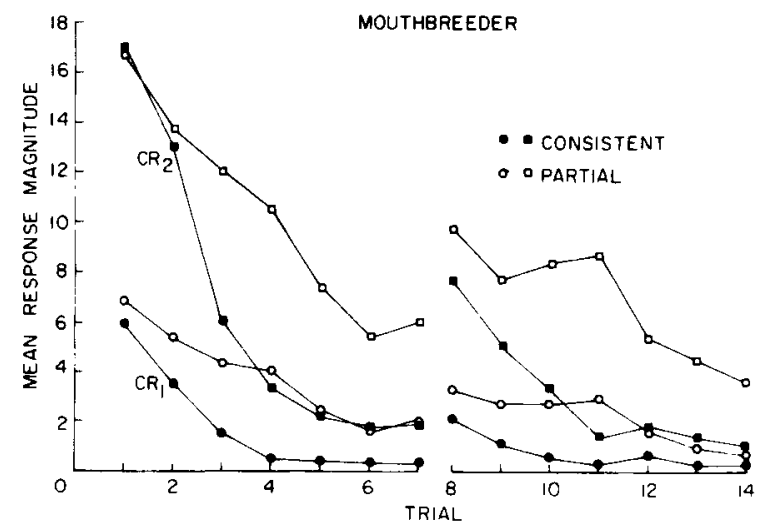

Fig. 1. The course of extinction in the first 14 trials for the two groups of mouthbreeders. The two different measures are described in the text. interval of $4.5 \mathrm{sec}$, a US of $0.5 \mathrm{sec}$ overlapped by the CS, and a variable ITI of 2-4 min which averaged $3 \mathrm{~min}$. The Consistent groups-one of each species-had five reinforced trials per day. The Partial groups were trained like the Consistent groups for the first eight days; for the next 12 days, they had 10 trials per day-five reinforced and five unreinforced-in Gellermann orders. There followed seven days of extinction for all groups, with seven unreinforced trials on each day.

Results. The course of acquisition in both species was much like that in the mouthbreeders of the earlier experiment. In extinction, the mouthbreeders again showed the PRE ( $F$ for Groups $=4.98, \mathrm{df}=1 / 40, \mathrm{p}<.05 ; \mathrm{F}$ for Groups by Days $=4.31$, $\mathrm{df}=4 / 160, \mathrm{p}<.01)$, while the goldfish did not $(\mathrm{F}<1)$. Trial-by-trial extinction curves for the first two days of extinction are plotted for the mouthbreeders in Fig. 1 and for the goldfish in Fig. 2. Two measures are used: $\mathrm{CR}_{1}$, the mean magnitude of response in $4.5 \mathrm{sec}$ (the measure on which the analyses reported above were based), and $\mathrm{CR}_{2}$, the mean magnitude of response in $9.5 \mathrm{sec}$ (response in the first interval plus response in a subsequent 5 -sec interval-the last $0.5 \mathrm{sec}$ of the CS followed by $4.5 \mathrm{sec}$ of darkness-programmed during training to measure response to the US). The PRE is shown by both measures in the mouthbreeders, but by neither measure in the goldfish.

Discussion. The results for mouthbreeders show again that the PRE occurs in classical conditioning, and there is no reason to believe that it is produced by processes other than those which operate in instrumental experiments. From this point of view, any failure to find the effect in a classical experiment must be due simply to the failure to provide conditions favorable to the operation of those processes. To the extent that sensory carryover and stimulus generalization are responsible for the PRE, its less frequent appearance in classical as compared with instrumental experiments may mean only that the sensory consequences of reinforcement and nonreinforcement on a previous trial are less discriminable in classical conditioning, either because they dissipate more rapidly in time, or because they are masked by powerful situational components as, for example, feedback from the fear which is conditioned to apparatus cues when a noxious US is employed.

The difference between the results for goldfish and mouthbreeders, which is unlikely to reflect a difference in basic learning mechanisms, may be approached in the same terms. It will be of interest to see whether the PRE can be produced in goldfish by classical procedures designed to maximize the discriminability of after-effects. It is perhaps unnecessary to note that the conditioned-frustration interpretation of the instrumental PRE does not guide us in our search for the effect in classical conditioning with a noxious US.

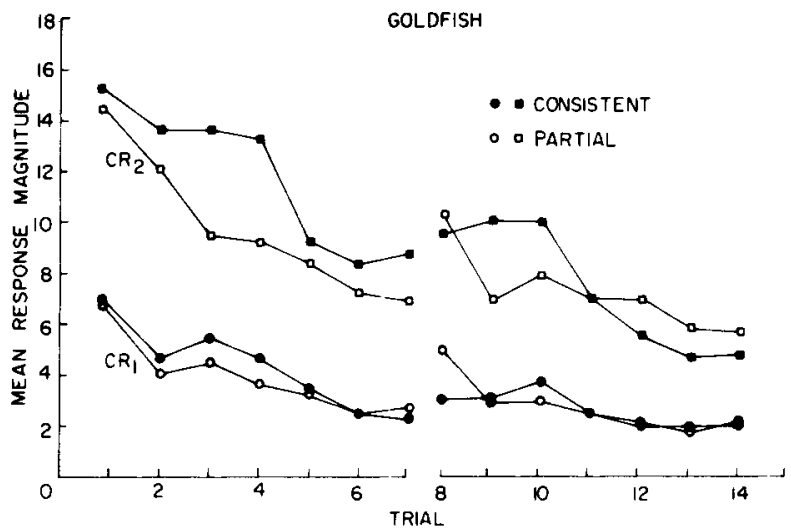

Fig. 2. The course of extinction in the first 14 trials for the two groups of goldfish. The two different measures are described in the text. 


\section{REFERENCES}

BITTERMAN, M. E. Classical conditioning in the goldfish as a function of the CS-US interval. J. comp. physiol. Psychol, 1964, 58, 359-366.

BERGER, B. D., YARCZOWER, M., \& BITTERMAN, M. E. Effect of partial reinforcement on the extinction of a classically conditioned response in the goldfish. J. comp. physiol. Psychol., 1965, 59, 399-405.

FITZGERALD, R. D. Some effects of partial reinforcement with shock on the classically conditioned heart rate in dogs. Amer. J. Psychol., 1966, 79 , 242-249.

GONZALEZ, R. C., \& BITTERMAN, M. E. Partial reinforcement effect in the goldfish as a function of amount of reward. J. comp. physiol. Psychol, $1967,64,163-167$.

GONZALEZ, R. C., ESKIN, R. M., \& BITTERMAN, M. E. Further experiments on partial reinforcement in the fish. Amer. J. Psychol, 1963, $76,366-375$.

SLIVKA, R. M., \& BITTERMAN, M. E. Classical appetitive conditioning in the pigeon: Partial reinforcement. Psychon. Sci., 1966, 4, 181-182.

THOMAS, E., \& WAGNER, A. R. Partial reinforcement of the classically conditioned eyelid response in the rabbit. J. comp. physiol. Psychol., 1964 , $58,157-158$.

WAGNER, A. R., SIEGEL, L. S., \& FEIN, G. G. Extinction of conditioned fear as a function of percentage of reinforcement. $J$. comp. physiol. Psychol., 1967, 63, 160-164.

\section{NOTE}

1. This research was supported by Grant MH-02857 from the U. S. Public Health Service. 